\title{
Heat-Generating Behavior of SiC Fiber Mat Composites Embedded with Ceramic Powder for Heat Conservation
}

\author{
Young Jun Joo**** and Kwang Youn Cho $\mathbb{D} * ;$ \\ *Fibrous Ceramics \& Aerospace Materials Center, Convergence R\&D Division, Korea Institute of Ceramic Engineering \\ and Technology, Jinju 52851, Korea \\ **Division of Nano \& Advanced Materials Engineering, Gyeongsang National University, Jinju 52828, Korea
}

(Received September 28, 2019; Revised October 23, 2019; Accepted October 23, 2019)

\begin{abstract}
Silicon carbide ( $\mathrm{SiC}$ ) fiber mats generate large amounts of heat through microwave interactions and are used as heating elements in rapid heat treatment furnaces. However, SiC fibers cool immediately when the microwave power is turned off. Therefore, ceramic layers are inserted between the $\mathrm{SiC}$ fiber layers to improve the heat conservation performance of $\mathrm{SiC}$ fiber mats. In this study, we fabricated SiC fiber mat composites (SMCs) with ceramic layers under various pressures. The SMC fabricated under $0.007 \mathrm{kPa}$ showed the lowest heat-generating temperature and deviation because less necking was observed between the materials. On the other hand, the SMC fabricated under $0.375 \mathrm{kPa}$ showed the highest heat-generating temperature of 1532.33 ${ }^{\circ} \mathrm{C}$. The SMCs prepared in this study using ceramic powder not only showed heat-generating temperatures comparable to those of conventional $\mathrm{SiC}$ fiber mats but also exhibited excellent heat-preserving ability.
\end{abstract}

Key words : SiC fiber, Ceramic powder, Microwave, Composites, Heat-conservation

\section{Introduction}

$\mathrm{C}$ onventional ceramic materials such as oxides, carbides, and nitrides have been extensively used as structural materials owing to their excellent chemical and high-temperature heat resistance. ${ }^{1,2)}$ However, ceramics suffer from safety and reliability problems, particularly in the aerospace and automobile fields, because of their low fracture toughness and ductility. ${ }^{3,4)}$ Therefore, composite materials, which show excellent mechanical strength, are used for manufacturing functional composite materials, and hence are promising materials for industrial applications. ${ }^{5-7)}$

Carbon fibers and $\mathrm{SiC}$ fibers are the most common inorganic fibers used as reinforcing materials for high-temperature resistant ceramic matrix composites (CMCs). ${ }^{3,4,8)}$ Carbon fibers are relatively inexpensive compared to $\mathrm{SiC}$ fibers but decompose in air at temperatures higher than $400^{\circ} \mathrm{C}$ because of their reaction with oxygen. On the other hand, $\mathrm{SiC}$ fibers exhibit high-temperature oxidation resistance even in air because of the presence of a large number of covalent bonds $(\sim 88 \%)^{9}{ }^{9}$

Polymer-derived silicon carbide (SiC) fibers are promising high-temperature and high-efficiency heating elements and structural materials. ${ }^{10,11)}$ Upon interaction with microwave

\footnotetext{
${ }^{\top}$ Corresponding author: Kwang Youn Cho

E-mail : kycho@kicet.re.kr

Tel : +82-55-792-2710 Fax : +82-55-790-2530

ORCID

https://orcid.org/0000-0002-4367-1408
}

energy, amorphous $\mathrm{SiC}$ fibers generate heat (above $1400^{\circ} \mathrm{C}$ ) in about 40-60 s. Moreover, these fibers exhibit long lifetimes without burning or melting at temperatures as high as $1400^{\circ} \mathrm{C}$ owing to their high heat resistance. Hence, the heat-generating behavior of polymer-derived SiC fibers has been investigated extensively to realize their heating element applications for rapid heat treatment.

Amorphous and crystalline SiC fibers are mainly derived from polymers, and polycarbosilane (PCS) is the commonly used SiC precursor. ${ }^{12,13)}$ PCS, which shows an average molecular weight of 3000-4000, is spun in the form of fibers by melt-spinning. These thermoplastic fibers are then converted into thermosetting fibers via a curing process. Finally, the cured PCS fibers are pyrolyzed at $1000-1400^{\circ} \mathrm{C}$ under an inert atmosphere to convert them into $\mathrm{SiC}$ fibers. ${ }^{14)}$ A single-filament of amorphous SiC fibers fabricated at $1300^{\circ} \mathrm{C}$ usually has a diameter of $10-15 \mu \mathrm{m}$ and a tensile strength of $1.5-2.0 \mathrm{GPa} .^{15,16)}$

Porphyry, also known as barley stone, is a type of volcanic rock and contains silica $\left(\mathrm{SiO}_{2}\right)$ and aluminum oxide $\left(\mathrm{Al}_{2} \mathrm{O}_{3}\right)$ as the main components. Barley stone is known to absorb and decompose harmful substances and can emit far-infrared (IR) rays that can penetrate 80 times deeper than normal heat. ${ }^{17)}$ In this study, a fine ceramic powder prepared by grinding barley stone was inserted into $\mathrm{SiC}$ fiber mats to preserve the generated heat by the interaction of $\mathrm{SiC}$ fibers with microwave energy. In addition, as the heat-generating behavior of $\mathrm{SiC}$ fibers changes under the application of pressure during the heat treatment process, ${ }^{10)}$ the pyrolysis process was carried out under different pressures to analyze 
the heat-generating behavior of the $\mathrm{SiC}$ fibers in terms of their bonding with the ceramic powder.

\section{Experimental Procedure}

\subsection{Preparation of PCS and cured PCS fibers}

PCS was used as the ceramic precursor and was purchased from TBMTech. Co. Ltd. (Korea). The polymer properties of PCS are summarized in Table 1. PCS, which has a melting point of about $170-180^{\circ} \mathrm{C}$, was melt-spun into fibers using a single-hole spinning machine. The curing process is essential for the polymer-to-ceramic transition of PCS fibers while maintaining the fiber shape. In this study, chemical vapor curing was used to cure the PCS fibers with low melting point $\left(<200^{\circ} \mathrm{C}\right) .{ }^{18,19)}$ Therefore, PCS fibers with $20-25$ $\mu \mathrm{m}$ were prepared in a graphite crucible at a ratio of $1: 1$ with iodine (CAS No. 7553-56-2, DaeJung Chemical, Korea). The obtained fibers were then heat-treated at $180^{\circ} \mathrm{C}$ for $2 \mathrm{~h}$.

Table 1. The Characteristics of PCS Measured by Gel Permeation Chromatograph and Melting Point Analyzer

\begin{tabular}{ccccc}
\hline $\mathrm{M}_{\mathrm{w}}$ (Daltons) & $\mathrm{M}_{\mathrm{n}}$ (Daltons) & $\mathrm{D}_{\mathrm{p}}$ & $\mathrm{T}_{\mathrm{s}}\left({ }^{\circ} \mathrm{C}\right)$ & $\mathrm{T}_{\mathrm{m}}\left({ }^{\circ} \mathrm{C}\right)$ \\
\hline 3614 & 1378 & 2.62 & 136 & $170-180$ \\
\hline
\end{tabular}

$\mathrm{M}_{\mathrm{w}}$ : weight average molecular weight, $\mathrm{M}_{\mathrm{n}}$ : number average molecular weight, $\mathrm{D}_{\mathrm{p}}$ : polydispersity, $\mathrm{T}_{\mathrm{s}}$ : softening point, and $\mathrm{T}_{\mathrm{m}}$ : melting point

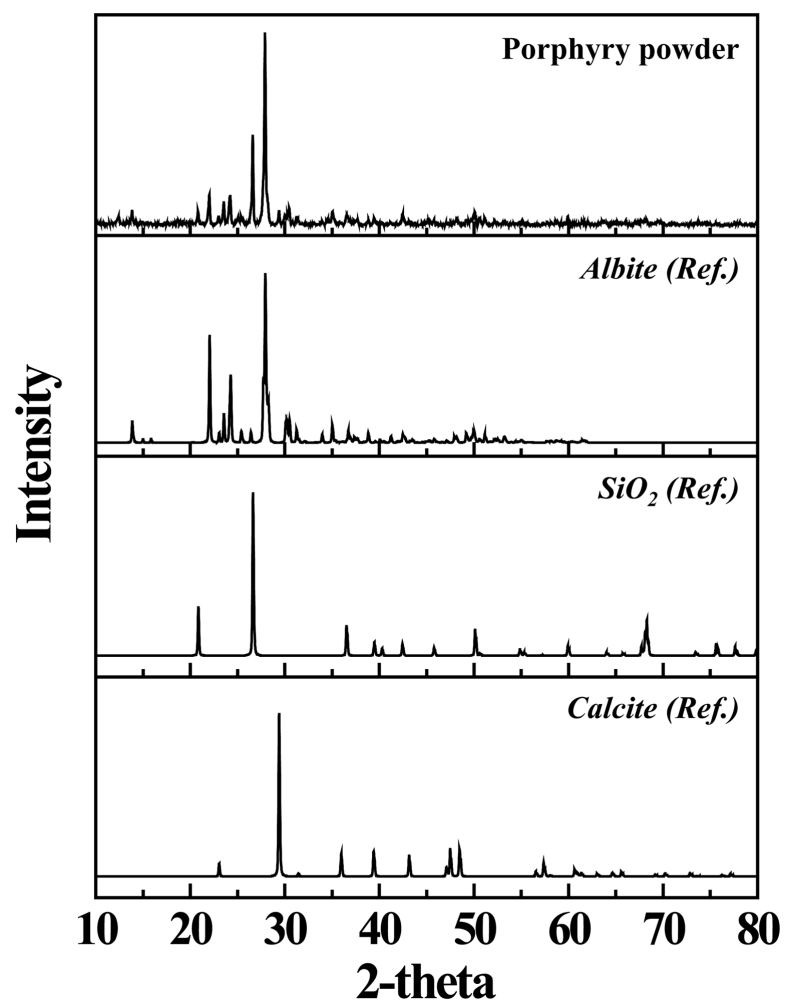

Fig. 1. X-ray diffraction pattern of purchased porphyry and reference materials.

\subsection{Preparation of SiC fiber mats embedded with ceramic powder}

Porphyry was used as the ceramic material for heat conservation and was purchased from SaeroQueen Co. (Korea). Fig. 1 shows the X-ray diffraction pattern (XRD) of porphyry and the reference materials. The ceramic powder prepared by grinding porphyry consisted mainly of the albite $(2 \theta=$ $27.91^{\circ}, 22.02^{\circ}, 27.94^{\circ}$, etc. $)$ and silicon oxide $\left(2 \theta=26.63^{\circ}\right.$, $20.85^{\circ}, 36.52^{\circ}$, etc.) phases.

A graphite mold having a diameter of $60 \mathrm{~mm}$ was prepared to fabricate a circular mat composite. A five-layered fiber mat composite was fabricated by stacking three layers of the cured PCS fibers and two layers of the ceramic powder alternately on the graphite mold. The SiC fibers:ceramic powder ratio of the fiber composite was about 0.5-1.0 weight ratio. The composite composed of the cured PCS fibers and ceramic powder was converted to a $\mathrm{SiC}$ fiber mat composite (SMC) by heat-treatment at $1300^{\circ} \mathrm{C}$ for $2 \mathrm{~h}$ in an inert atmosphere. After the heat treatment, the ceramic yield of the PCS fibers was 81 wt.\% and the weight loss of the ceramic powder was $6.5 \mathrm{wt} . \%$.

During the pyrolysis process at $1300^{\circ} \mathrm{C}$, the graphite molds were subjected to different pressures of $0.007,0.375,0.749$, and $1.124 \mathrm{kPa}$ and the SMCs fabricated at these pressures were labelled as SMC-1, SMC-2, SMC-3, and SMC-4, respectively. A SiC fiber mat without the ceramic powder was also fabricated at $0.375 \mathrm{kPa}$ in order to investigate the effect of the embedded ceramic powder on the thermal characteristics of the fiber mats.

\subsection{Measurements}

The melting point of PCS was measured using a digital melting point instrument (IA9100, Bibby Scientific Co. Ltd., USA). A small amount of PCS was placed in a capillary tube, whose temperature was raised at $10^{\circ} \mathrm{C} / \mathrm{min}$ until the softening point was reached. After reaching the softening point, the temperature was raised at $1^{\circ} \mathrm{C} / \mathrm{min}$ to measure the melting point. Gel permeation chromatography (GPC) analysis was carried out on a system equipped with a Waters 515 HPLC pump, a Waters 2414 refractive index detector, and a series of three Shodex HPLC columns. The GPC instrument was calibrated using polystyrene standards and toluene as the solvent at the flow rate of $1 \mathrm{~mL} / \mathrm{min}$. The XRD analysis (DMAX 2500, Rigaku, Japan) of the polymer-derived $\mathrm{SiC}$ fiber fabricated at $1300^{\circ} \mathrm{C}$ for $2 \mathrm{~h}$ and the ceramic powder was carried out using $\mathrm{Cu} K \alpha$ radiation over the $2 \theta$ range of $10-80^{\circ}$. The heat-generating behaviors of the $\mathrm{SiC}$ fiber mat and SMCs (containing the ceramic powder) were investigated using a microwave generation system (DAEHO I\&T Co. Ltd., Korea) equipped with one magnetron (2.45 GHz). The maximum heat-generating temperature and temperature distribution of the samples under microwave were determined using an IR camera (HotFind DXS, SDS, Europe). The joining interface between the fiber and ceramic powder layers of the SMCs was observed using scanning electron microscopy (SEM) (EM-30AX, COXEM, Korea). 
(a)

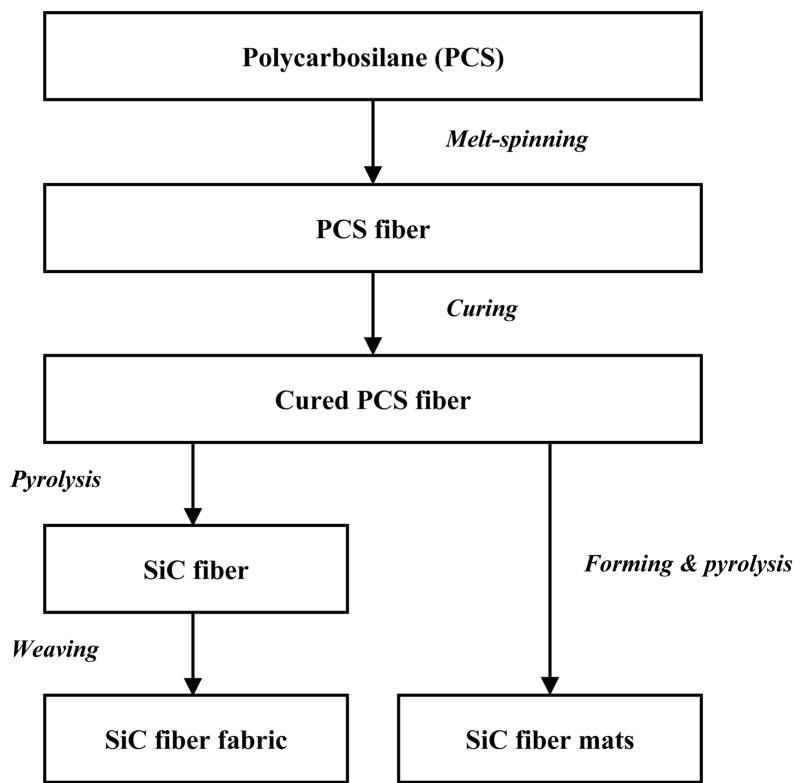

(b)

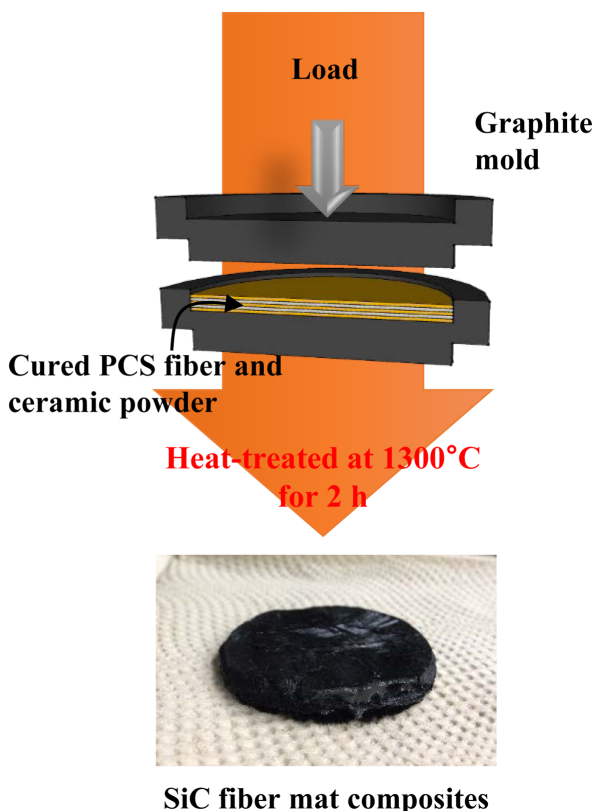

Fig. 2. (a) Flow diagram and (b) schematic drawing of the methods for making three-dimensional structures using SiC fibers.

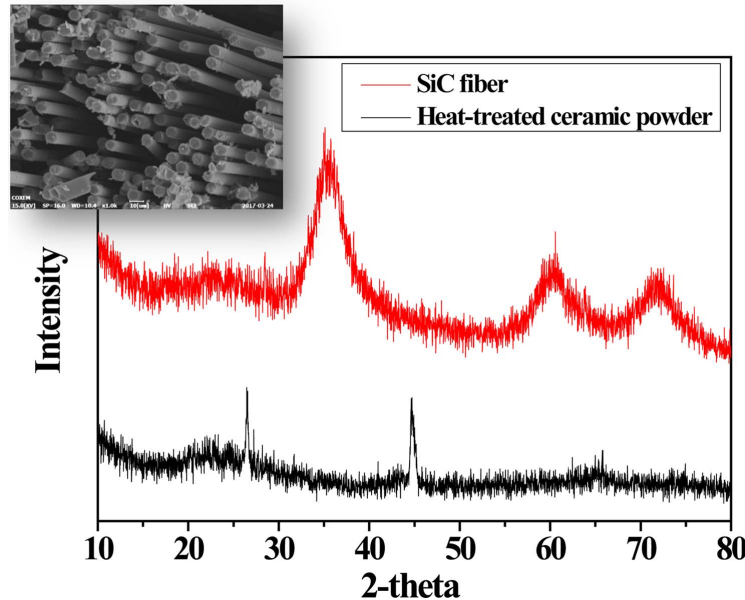

Fig. 3. XRD patterns of polymer-derived SiC fiber and commercial ceramic powder after the heat-treated at $1300^{\circ} \mathrm{C}$ for $2 \mathrm{~h}$ in an inert atmosphere. Inset SEM image show the shape of the SiC fibers.

\section{Results and Discussion}

SiC fiber fabrics are generally woven using continuous fibers. The weaving of these fabrics is a complex and expensive process. However, in this study, the mat composites were fabricated simply by cutting and stacking the cured PCS fibers and ceramic powder before the formation of SiC fibers, as shown in Fig. 2(a). Hence, the SMCs containing the ceramic powder could be easily fabricated by simply applying pressure, as shown in Fig. 2(b).

Figure 3 shows the XRD pattern of the $\mathrm{SiC}$ fiber fabricated at $1300^{\circ} \mathrm{C}$ for $2 \mathrm{~h}$ in an inert atmosphere and the purchased ceramic powder. The amorphous SiC fiber obtained

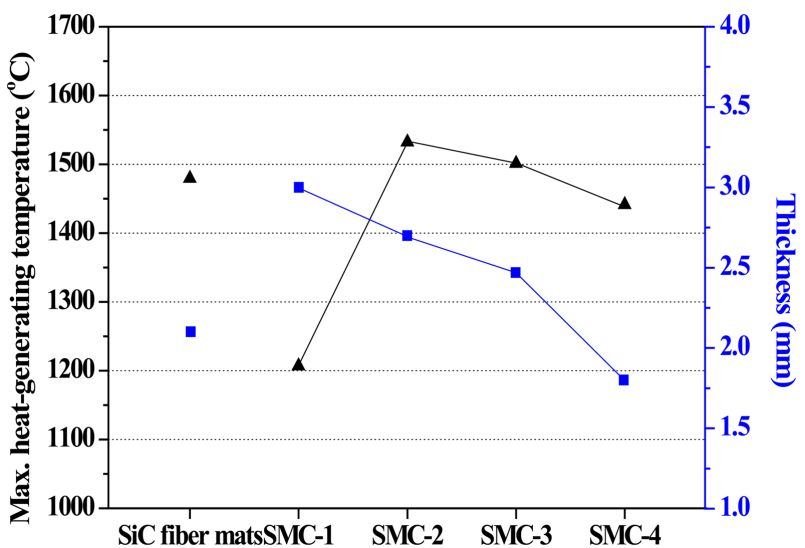

Fig. 4. The maximum heat-generating temperature and thickness of SiC fiber mats and SCMs fabricated at $1300^{\circ} \mathrm{C}$ for $2 \mathrm{~h}$

at $1300^{\circ} \mathrm{C}$ showed broad $\mathrm{B}$-SiC phase peaks at $2 \theta=35.74^{\circ}$, $60.26^{\circ}$, and $72.03^{\circ}$. Uniform and round shape via inserted SEM image. As the ceramic powder was melted at a relatively low temperature by the alkali system, it showed an amorphous phase and weak $\mathrm{SiO}_{2}$ (at $2 \theta=26.71^{\circ}$; maganite) and $\mathrm{Fe}\left(\right.$ at $2 \theta=44.68^{\circ}$ and $65.03^{\circ}$ ) peaks.

It has been reported that the heat-generating behavior of $\mathrm{SiC}$ fiber sheets fabricated via electrospinning depends on the sheet thickness and the number of $\mathrm{SiC}$ fiber layers. ${ }^{10,11)}$ Therefore, the thickness of the SMCs prepared under different pressures was controlled (during the heat treatment process under the inert atmosphere) in this study.

The maximum heat-generating temperatures of the SMCs under the microwave exposure were measured using an IR camera, as shown in Fig. 4. The microwave power was adjusted by increasing the current from 0 to $6.5 \mathrm{~A}$ at $220 \mathrm{~V}$. 
Table 2. Heat-generating Characteristics of SiC Fiber Mats and SiC Fiber Mat Composites Measured Using Infrared Camera

\begin{tabular}{cccccc}
\hline & \multirow{2}{*}{ SiC fiber mats } & \multicolumn{3}{c}{ SiC fiber mat composites } \\
\cline { 3 - 6 } & & Load-6 & Load-300 & Load-600 & Load-900 \\
\hline IR image & & & & & \\
& & & & & \\
Average temperature $\left({ }^{\circ} \mathrm{C}\right)$ & 1308.49 & 776.44 & 1242.92 & 185.06 & 1203.17 \\
Standard deviation $(\%)$ & 9.35 & 38.82 & 9.35 & 10.38 & 9.07 \\
\hline
\end{tabular}

(a)

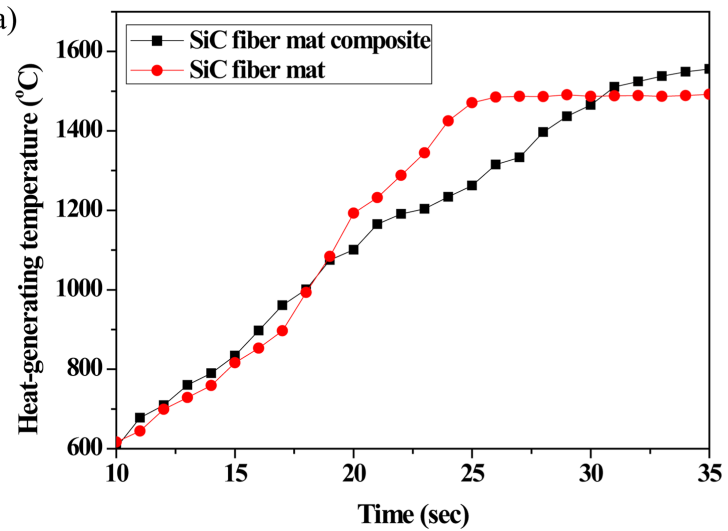

(b)

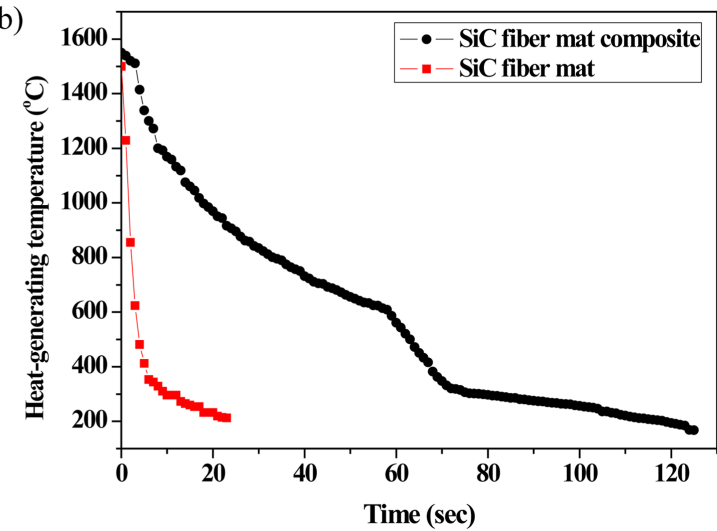

Fig. 5. (a) Heating rate depending on the interaction with microwave and (b) cooling rate after switching off the microwave power of SiC fiber mat and $\mathrm{SiC}$ fiber mat composite.

The maximum heat-generating temperature of the $\mathrm{SiC}$ fiber mat fabricated without the ceramic powder was $1479.68^{\circ} \mathrm{C}$. On the other hand, the SMC-1, SMC-2, SMC-3, and SMC-4 samples showed the maximum heat-generating temperatures of $1206.80,1532.33,1501.13$, and $1441.49^{\circ} \mathrm{C}$, respectively. With an increase in the pressure applied during the heat treatment, the thickness of the SMC samples decreased from about 2.7 to $1.8 \mathrm{~mm}$. The heat-generating temperature of the SMCs first increased with an increase in the applied pressure up to $0.375 \mathrm{kPa}$ and then decreased. This is because the ceramic powder penetrated the $\mathrm{SiC}$ fibers under excessive pressure, which reduced the necking of the $\mathrm{SiC}$ fibers. $^{10)}$

The heat-generating characteristics for the fiber mat and
SMCs are summarized in Table 2. The SiC fiber mat without the ceramic powder consisted of a single material only. This mat showed the highest average heat-generating temperature among all the samples. SMC-1 on the other hand, showed heterogeneous heat-generating temperature because of the poor bonding between the inserted ceramic powder and the SiC fibers. Therefore, with an increase in the pressure applied during the heat treatment, the average temperature of the SMCs increased.

All the samples were observed in real-time using an IR camera under microwave exposure to investigate the effect of the ceramic powder on the heating and cooling rates of the samples. As can be observed from Fig. 5(a), the SiC fiber mat took about $25 \mathrm{~s}$ to reach the maximum heat-generating
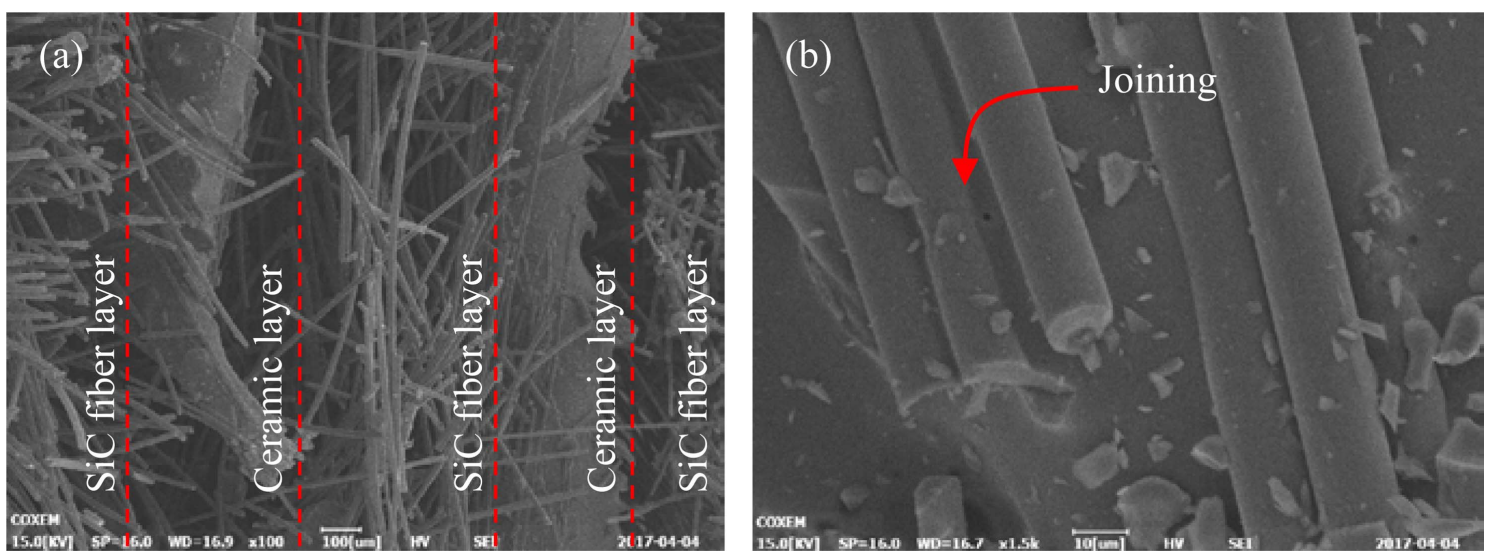

Fig. 6. SEM images of $\mathrm{SiC}$ fiber mat composite embedded with ceramic powder. 
temperature. On the other hand, the SMCs took approximately $15 \mathrm{~s}$ longer than the $\mathrm{SiC}$ fiber mat because they consumed energy to heat the inserted ceramic powder. In case of the cooling rate, the SMCs radiated heat at temperatures higher than $200^{\circ} \mathrm{C}$ for $120 \mathrm{~s}$ because of the presence of the ceramic powder, which showed heat conservation capability. Fig. 5(b) shows the difference in the cooling rates of the $\mathrm{SiC}$ fiber mat and SMCs. The SiC fiber mat cooled rapidly because of its high thermal conductivity and large specific surface area, while the SMCs showed significantly improved heat conservation because of the presence of porphyry powder, which receives heat from the surroundings and emits far-IR rays.

Figure 6 shows the SEM images of the cross-section and surface of the SMCs containing the ceramic powder. When the SMCs were cut vertically for the cross-sectional observation, a gap was formed between the layers because the mechanical bond was broken. This indicates that the powder did not penetrate deep into the fiber layer. As can be observed from Fig. 6(b), the ceramic powder melted during the heat treatment process and formed a layer between the SiC fiber layers. In addition, the ceramic layer was bonded to the shallow surface of the fiber layer.

\section{Conclusions}

A ceramic powder composed mainly of the albite and $\mathrm{SiO}_{2}$ phases was embedded between polymer-derived $\mathrm{SiC}$ fibers to prepare $\mathrm{SiC}$ fiber mats generating heat under microwave irradiation. SMCs were easily prepared by alternately stacking the cured PCS fibers and ceramic powder and then heat-treating the resulting assembly in an inert atmosphere under various pressures. The heat-generating properties of the SMCs with the ceramic powder depended on the pressure applied during the heat treatment. The SMC prepared under $0.375 \mathrm{kPa}$ showed a temperature deviation of $9 \%$ and the highest heat-generating temperature of $1532^{\circ} \mathrm{C}$ in about $30 \mathrm{~s}$. In addition, the SMCs radiated heat at temperatures higher than $200^{\circ} \mathrm{C}$ over a long period of time as compared to the SiC fiber mats. Therefore, the SMCs prepared in this study by mechanical bonding with the ceramic powder through high-temperature heat treatment are promising high-efficiency and ultra-high temperature heating elements.

\section{Acknowledgments}

This work was financially supported by the Korea Institute of Ceramic Engineering and Technology (KICET) and Ministry of Trade, Industry and Energy (MOTIE:P0010094) of the South Korea government.

\section{REFERENCES}

1. V. V. Vikulin, I. Y. Kelina, A. S. Shatalin, and L. N. Rusanova, "Advanced Ceramic Structural Materials," Refract. Ind. Ceram., 45 [6] 383-86 (2004).
2. U. Täffner, V. Carle, U. Schäfer, and M. J. Hoffmann, "Preparation and Microstructural Analysis of High-Performance Ceramics"; pp. 1057-66 in Metallography and Microstructures, Vol. 9, Metallography and Microstructures of Ceramics, Composite-Metal Forms, and Special Purpose Alloys. Ed. by G. V. Voort, ASM International, USA, 2004.

3. R. Naslain, "Design, Preparation and Properties of NonOxide CMCs for Application in Engines and Nuclear Reactors: An Overview," Compos. Sci. Technol., 64 [2] 155-70 (2004).

4. B. Budiansky and J. W. Hutchinson, "Matrix Fracture in Fiber-Reinforced Ceramics," J. Mech. Phys. Solids, 34 [2] 167-89 (1986).

5. E. Bernardo, L. Fiocco, G. Parcianello, E. Storti, and P. Colombo, "Advanced Ceramics from Preceramic Polymers Modified at the Nano-Scale: A Review," Materials, 7 [3] 1927-56 (2014)

6. A. Muc and M. Barski, "Design of Particulate-Reinforced Composite Materials," Materials, 11 [2] 234 (2018).

7. F. Lenz and W. Krenkel, "Carbon Fiber Reinforced Ceramics based on Reactive Melt Infiltration Processes," J. Korean Ceram. Soc., 49 [4] 287-94 (2012).

8. S. Schmidt, S. Beyer, H. Knabe, H. Immich, R. Meistring, and A. Geessler, "Advanced Ceramic Matrix Composite Materials for Current and Future Propulsion Technology Applications," Acta Astronaut., 55 [3-9] 409-20 (2004).

9. V. A. Izhevskyi, L. A. Genova, J. C. Bressiani, and A. H. Bressiani, "Review Article: Silicon Carbide. Structure, Properties and Processing," Cerâmica, 46 [297] 4-13 (2000).

10. K. E. Khishigbayar, J. M. Seo, and K. Y. Cho, "Heating Behavior of Silicon Carbide Fiber Mat under Microwave," J. Korean Ceram. Soc., 53 [6] 707-11 (2016).

11. K. E. Khishigbayar, Y. J. Joo, and K. Y. Cho, "MicrowaveAssisted Heating of Electrospun SiC Fiber Mats," J. Korean Ceram. Soc., 54 [6] 499-505 (2017).

12. S. Yajima, Y. Hasegawa, J. Hayashi, and M. Iimura, "Synthesis of Continuous Silicon Carbide Fibre with High Tensile Strength and High Young's Modulus Par 1 Synthesis of Polycarbosilane as Precursor," J. Mater. Sci., 13 [12] 2569-76 (1978).

13. R. Usukawa, H. Oda, and T. Ishikawa, "Conversion Process of Amorphous Si-Al-C-O Fiber into Nearly Stoichiometric SiC Polycrystalline Fiber," J. Korean Ceram. Soc., 53 [6] 610-4 (2016).

14. Y. Hasegawa and K. Okamura, "Synthesis of Continuous Silicon Carbide Fibre Part 3 Pyrolysis Process of Polycarbosilane and Structure of the Products," J. Mater. Sci., 18 [12] 3633-48 (1983).

15. A. R. Bunsell and A. Piant, "A Review of the Development of Three Generations of Small Diameter Silicon Carbide Fibres," J. Mater. Sci., 41 [3] 823-39 (2006).

16. D. G. Shin, D. H. Riu, Y. H. Kim, H. R. Kim, H. S. Park, and H. E. Kim, "Characterization of SiC Fiber Derived from Polycarbosilanes with Controlled Molecular Weight," J. Korean Ceram. Soc., 42 [8] 593-98 (2005).

17. Y. S. Han, H. J. Kim, Y. S. Shin, J. K. Park, and J. C. Ko, "Silver Coating on the Porous Pellets from Porphyry rock and Application to an Antibacterial Media," J. Korean 
Ceram. Soc., 46 [1] 16-26 (2009).

18. J. S. Hong, K. Y. Cho, D. G. Shin, J. I. Kim, S. T. Oh, and

D. H. Riu, "Low-Temperature Chemical Vapour Curing Using Iodine for Fabrication of Continuous Silicon Carbide Fibres from Low-Molecular-Weight Polycarbosilane,"
J. Mater. Chem. A, 2 [8] 2781-93 (2014).

19. J. S. Hong, K. Y. Cho, D. G. Shin, J. I. Kim, and D. H. Riu, "Iodine Diffusion during Iodine-Vapor Curing and its Effects on the Morphology of Polycarbosilane/Silicon Carbide Fibers," J. Appl. Polym. Sci., 132 [47] 42687 (2015). 